\title{
The first experience of liver transplantation in children
}

\author{
Batyrly Tuleubay ${ }^{1}$, Zhakanov Tuleu ${ }^{2}$, Aulybay Dauken ${ }^{2}$
}

${ }^{1}$ JSC "Medical University of Astana;

${ }^{2}$ City Children's Hospital enterprise on economic management №2 of Astana city

УДК 616.361:617.053

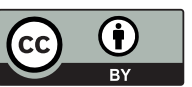

This work is licensed under a Creative Commons Attribution 4.0 International License

\section{J CLIN MED KAZ 2017; 3(45 SUPPL 3):89-91}

Автор для корреспонденции: Дженалаев Дамир Булатович, д.м.н., руководитель отдела детской хирургии Корпоративного фонда «University Medical Center «Национальный научный центр материнства и детства», Адрес: 010000 Казахстан, г.Астана, пр.Туран, 32. тел: 8(701) 522-12-89, e-mail - damir1972@mail.ru
БАЛАЛАР БАУЫР ТРАНСПЛАНТАЦИЯСЫ АЛҒАШҚЫ ТӘЖІРИБЕСІ Женалаев Д.Б. ${ }^{1}$, Мұстафинов Д.А. ${ }^{1}$, Мамлин О.А. ${ }^{1}$, Түрлібекова С.С. ${ }^{1}$, Сапаров А.И. ${ }^{1}$, Аникин В.В. ${ }^{1}$, Мұстафинова Г.Т. ${ }^{1}$

"University Medical Center" корпоративтік қорының «Ана мен бала ұлттық ғылыми орталығы»

\section{ПЕРВЫЙ ОПЫТ ВЫПОЛНЕНИЯ ТРАНСПЛАНТАЦИИ ПЕЧЕНИ У ДЕТЕЙ}

Дженалаев Д.Б. ${ }^{1}$, Мустафинов Д.А. ${ }^{1}$, Мамлин О.А. ${ }^{1}$, Турлибекова С.С. ${ }^{1}$, Сапаров А.И. ${ }^{,}$, Аникин В.В. ${ }^{1}$, Мустафинова Г.Т. ${ }^{1}$

Корпоративный фонд «University Medical Center «Национальный научный центр материнства и детства

\section{Введение}

В настоящее время пересадка печени является второй по частоте трансплантационной операцией в мире. Ежегодно растет число выполняемых трансплантаций печени[1, 2, 3].

Учитывая растущую потребность в пересадке печени,большинство исследователей считают, что со временем операции трансплантации печени могут занять лидирующее место $[4,5]$.

Абсолютными показаниями к пересадке печени служат:

- Терминальные стадии цирроза печени.

- Быстро прогрессирующие формы хронической печеночной недостаточности.

Относительные показания к трансплантации печени:

- Хроническое диффузное дистрофическое заболевание печени, при котором ожидаемая продолжительность жизни составляет менее 1 года.

- Ц Цирроз печени с энцефалопатией.

- Цирроз печени с повторными кровотечениями из расширенных вен пищевода.

- Цирроз печени, сопровождающийся гепаторенальным синдромом, устойчивым асцитом, нарастающей печеночной недостаточностью.

- Очаговое заболевание печени, при котором технически невозможна резекция (из-за большого очага или при множественных очагах).

- Прочие (в целом более 50) $[6,7,8]$.

В Государственной программе развития здравоохранения «Саламатты Казахстан» на 2011-2015 годы одним из приоритетных направлений является развитие высокоспециализированной медицинской помощи, в том числе трансплантации органов (9). За последнее время в республике предпринимаются серьезные меры по развитию отечественной трансплантологии, которые позволяют из года в год увеличивать количество проводимых трансплантаций органов и тканей $[10,11,12]$.

В рамках развития этого направления на базе АO «Национальный Научный центр материнства и детства» с декабря 2014 года по январь 2017 года с участием коллег из университетской клиники г.Башкент (Турция) и клиники «Аполло» (Индия) проведено6 успешных трансплантаций детям в возрасте от 6 месяцев до 1 года.

Всем детям проведена родственная трансплантация от живого донора. Время наблюдения за пациентами после проведенной трансплантации составляет от 6 месяцев до 2,5 лет.

\section{Описание случая}

Ребенок С. 6 месяцев, поступил в отделение детской хирургии клинику АО «Национальный научный центр материнства и детства» 04.05.2015 года.

Жалобы при поступлении на желтушность кожных покровов, ахоличный стул, слабость, вялость.

Ребенок болен с рождения. Через 1 месяц после рождения выставлен диагноз «Атрезия желчевыводящих путей». Находился на диспансерном учете у педиатра и хирурга по месту жительства.

Состояние при поступлении тяжелое по заболеванию. Самочувствие страдает вследствие билирубиновой интоксикации. Кожные покровы, видимые слизистые желтушные. Ребенок правильного телосложения, пониженного питания. Вес- 7000 гр. Зев спокоен. Периферические лимфоузлы не увеличены. Дыхание через нос свободное. ЧД - 30 в 1 минуту. В легких пуэрильное дыхание, хрипов нет. Сердечные тоны ясные, ритм 
правильный. ЧСС - 132 в 1 мин. АД- 75/45 мм рт ст. Язык влажный, чистый. Область почек визуально и пальпаторно без особенностей. Костно-суставная система без видимой патологии. Стул обесцвеченный, кашицеобразный. Мочеиспускание свободное, безболезненное, темного цвета.

Status localis: Живот увеличен в объёме, при пальпации мягкий, доступный во всех отделах, безболезненный. Перистальтика кишечника активная. Печень увеличена, +4,0 из под реберной дуги, плотно-эластической консистенции, пальпаторно безболезненна. Селезенка пальпируется $+2,0$ из под левого ребра, эластичная, безболезненна.

В биохимическом анализе крови при поступлении: альбумин 40 г/л; АЛТ 77 ед/л; АСТ 183 ед/л; общий биллирубин 161,2 ммоль/л; прямой биллирубин 67,0 ммоль/л; ГГТП 83,1 ед/л; щелочная фосфатаза 445 ед/л; Коагулограмма: ПВ 14,6 сек; фибриноген 1,4 г/л; АЧТВ 39,2 сек; ТВ 23, 6сек; Протромбиновое время по Квику 57,8 $\%$, MHO 1,1

Ребенку проведено обследование:

ОАК, ОАМ, коагулограмма, биохимия крови, маркеры на гепатиты, ПЦР и ИФА на внутриутробные инфекции; проведено УЗИ ОБП, УЗИ щитовидной железы, ФГДС, ЭКГ, ЭХОКГ, КТ печени в ангиорежиме, МРТ печени в режиме холангиографии.

Ребенок осмотрен кардиологом, инфекционистом, консультирован гепатологом и трансплантологом: выставлен диагноз «Врожденный порок развития желчевыводящих путей. Цирроз печени», выставлены показания к трансплантации.

После проведенной предоперационной подготовки (инфузионная терапия, гемотрансфузия, инфузия 10\% альбумина, смекта, дюфалак, урсосан, витамин К, гептрал, ферталь, антибактериальная терапия).

18.05.2015 проведена операция «Трансплантация печени от донора» (мама). Гастропеченочная и серповидная связки печени были рассечены, после чего была мобилизована печень. Следующие этапы - мобилизация печени, выделение нижней полой вены, печеночной артерии и воротной вены. Анастомоз нижней полой вены реципиента с трансплантантом «конец в бок». Затем была анастомозирована воротная вена по типу конец в конец (Prolen 7.0) и были открыты сосудистые зажимы. Печеночная артерия трансплантата анастомозирована в печеночную артерию реципиента по типу конец в конец нитью (Prolen 7.0) непрерывным швом. Выполнено УЗГД, который показал поток артерии и потоки вен и воротной вены. Отмечается отхождение желчи по желчным путям трансплантанта. Введены введены дренажи в поддиафрагмальное пространство и малый таз. Наружные желчные пути анастомозированы с тощей кишкой на петле по Ру. Фасцию ушивалась отдельными узловыми швами одним слоем (Vikril 2.0). Отдельными узловыми швами нитью (Vikril 5.0) ушита подкожная клетчатка, на кожу субкутикулярный шов нитью (Vikril 3.0).

В послеоперационном периоде ребенок в течение 8 дней находился в отделении детской анестезиологии, реанимации и интенсивной терапии. Терапия проводилась в соответствии с проводимым мониторингом:

Каждый час: Артериальное давление, ЧСС по ЭКГ монитору, ЦВД, разница базовой/периферической температур, чрезкожное определение насыщения кислородом, баланс жидкостей, включая коллоиды, дренаж раны, объемы мочи и лекарств;

Каждые 4 часа в течение 24 часов, при необходимости: сывороточный натрий, калий, кальций, глюкоза и лактат в крови. $\mathrm{pH}$ в желудке определяется каждые 6 часов через назогастральный зонд (целевое значение $\mathrm{pH}>5$ );

УЗДГ - в течение первых 5 дней, далее - по клиническим показаниям;

Ежедневно:рентгенография органов грудной клетки, ОАК, протромбиновое время, АЧТВ, уровень такролимуса в крови, мочевина, креатенин, кальций, фосфаты, магний, точное измерение веса.

В послеоперационном периоде общий билирубин снизился на вторые сутки до 38,5 ммоль/л.

Иммуносупрессивная терапия проводилась препаратом Такролимус (Програф): 0.15 мг/кг/доза перорально дается в течение 6 часов после трансплантации; далее 0.075 мг/ кг/доза 2 раза в сутки перорально для достижения уровня такролимуса 10-15 нг/мл в течение первых 2 недель. Последовательно корректируется дозировку для достижения 8-12 нг/мл на третьей и четвертой неделях; 5-8 нг/мл на втором и третьем месяце;3-5 нг/мл в последующем.

Ребенок был выписан из стационара на 24 сутки от момента проведения операции. С периодичностью 1 раз в три месяца ребенок наблюдается в АО «ННЦМД». В настоящее время состояние ребенка ближе к удовлетворительному. Биохимические показатели, данные ультразвукового исследования в пределах нормы.

\section{Выводы}

Анализируя литературные данные и свой, пока незначительный опыт, можно отметить, что четкое соблюдение алгоритма клинического обследования, определение и соблюдение диагностических и лечебных критериев позволят улучшить показатели положительных исходов после операции и увеличить выживаемость данной категории пациентов.

\section{Литература:}

1. Jain A., Reyes J., Kashyap R. et al. Long-term survival after liver transplantation in 4000 consecutive patients at a single center. Ann. Surg. 2000. Vol. 232 (4): 490-500.

2. Malomuzh O.I. Hronicheskie zabolevanija pecheni: pokazanija i optimal'nye sroki gospitalizacii.[in Russian].Diss. k.m.n.Moskva. 2009; 114.

3. Got'e S.V Ortotopicheskaja transplantacija pecheni v lecheniiee diffuznyh i ochagovyh zabolevanij [inRussian]. Diss. dokt. med. nauk.-Moskva.1996;346.

4. ChzhaoA.V. Transplantacija pecheni. [in Russian]. Klinicheskaja gepatologija.2007; (3):22-27

5. Jonas M. Living-related liver transplantation. Review. Hepatology.2000; (33):431-438.

6. Karam V,Castaing D, Danet C, DelvartV,Gasquet I, Adam R. et all. Lonqitudial prospective evaluation of quality of life in adult patient before and one year after liver transplantation // Liver Transpl.-2003.-№9.- P.703-711.

7. Semenkov A.V. Rodstvennye donory dlja transplantacii pecheni: otbor, obsledovanie, hirurgicheskajataktika. [inRussian]. Diss. k.m.n..-Moskva. 2003;117. 
8. Sejsenbaev M.A., Toksanbaev D.S., Zajnalov A.K., Sadykov N.K., Doshanov M.O., Kaniev Sh.A., Isbambetov A.S., Balabekov A.G., Urkenova A.A. [inRussian]. Obshie voprosy klinicheskoj transplantacii pecheni v mirovoj praktikei v RespublikeKazahstan // Transplantologija v Kazahstane.2014; (1):7-9.

9. Gosudarstvennaja programma razvitija zdravoohranenija Respubliki Kazahstan «SalamattyҚаzaқstan» na 2011 - 2015 gody. [inRussian]

10. ArzykulovZh.A., Sejsembaev M.A., Toksanbaev D.S., Sadykov N.K., Dujsebekov M.K., Isbambetov A.S., Doshanov M.O. Formirovanieivedenie «listaozhidanija» transplantaciipecheni v AO «NNCH im.A.N.Syzganova» RespublikiKazahstan. [inRussian].Transplantologija v Kazahstane. 2014; (1):28.

11. Bajmahanov B.B., Chormanov A.T., Sahipov M.M., Kuandykov T.K., Mutagirov V.V., Il'jasova B.S., Birzhanbekov N.N., Astaj A.A., Stamkulov F.T. Pervyj opyt ortotopicheskoj rodstvennoj transplantacii pecheni v gorodskoj klinicheskoj bol'nice № 7 g.Almaty.[inRussian].Transplantologija v Kazahstane.2014; (1):37-38.

12. Toksanbaev D.S., Sadykov N.K., Doshanov M.O., Dujsebekov M.K., KanievSh.A. Posttransplantacionnoe vedeniei nabljudenie recipientov pechenochnogo transplanta. [in Russian]. Transplantologija v Kazahstane.2014; (1):29-30. 